\title{
Adsorptive and Catalytic Cathodic Stripping Voltammetric Determination of Timonacic
}

\author{
O.A.R. Amin, ${ }^{1, *}$ S.F. Belal ${ }^{2}$ and R. Bakry ${ }^{3}$ \\ ${ }^{1}$ Pharmaceutical Chemistry Department, Faculty of Pharmacy, King Abdulaziz University, \\ Saudi Arabia. \\ ${ }^{2}$ Pharmaceutical Analytical Chemistry Department, Faculty of Pharmacy, University of \\ Alexandria, Egypt. \\ ${ }^{3}$ Institute of Analytical Chemistry and Radiochemistry, Leopold Franzens University Innsbruck, \\ Innrain 52a, 6020 Innsbruck, Austria.
}

Received 13 October 2010; accepted 31 March 2011

\begin{abstract}
Two sensitive voltammetric techniques (adsorptive and catalytic cathodic stripping) are described for the determination of timonacic, in the presence of copper or nickel ions, respectively. The measured peaks which correspond to the reduction or copper (I) or nickel - timonacic complexes are measured at -773 and $-782 \mathrm{mV}$, respectively. The different experimental parameters have been carefully studied. The methods have been fully validated. The detection limits were 1.5 and $13.6 \mathrm{ng} \mathrm{mL} \mathrm{m}^{-1}$, respectively. The methods have been applied for the determination of timonacic in pharmaceutical tablets. The obtained results have been compared statistically with those obtained from a published method.
\end{abstract}

Keywords: timonacic; adsorptive stripping voltammetry; catalytic cathodic stripping voltammetry; pharmaceutical tablets.

\section{Introduction}

The timonacic (TC) molecule has a biological significance; its importance arises from the fact that the thiazolidine ring is an integral part of pharmacologically active compounds like penicillins and antiradiation drugs [1,2]. It plays an important role in hepatotoxicity protection, and is used as an adjuvant in the treatment of some kind of hepatic diseases, psoriasis and acne [3]. The drug has been used as an antitumor agent through induction of reverse transformation [4].

\footnotetext{
* Corresponding author. E-mail address: omarazak_amin @yahoo.com
} 
Few articles have been published for the analysis of TC in its pharmaceutical dosage forms. The drug has been determined through voltammetric techniques $[5,6]$ and current oscillopolarographic titration [7]. Spectrophotometric [8-11] and titrimetric [12] methods were applied for its determination. High performance liquid chromatographic methods were described for TC determination in plasma $[13,14]$. In urine or urine and serum, TC has been determined by GC-Ms [15] and capillary GC [16].

Florence [17] tested several organic sulphur compounds and reported that cyclic organic compounds were not cathodic stripping voltammetry (CSV) active. However, Karpiniski [18], and von Wandruszka [19], reported that TC, a thiazolidine derivative, gives a strong cathodic stripping peak. They suggested that the anodic accumulation process takes place through the thiazolidine ring opening due to the interaction of TC with mercury.

The sensitivity of the CSV increases in the presence of copper (II) and the determination will be through adsorptive stripping voltammetry (AdSV). The analyte at suitable accumulation potential gives a strongly adsorbed copper complex. The stripping peak is due to the reduction of copper in the complex. This method was applied for the determination of cysteine [20], penicillamine [21], glutathione [22] and histidine [23].

Another approach to increase the sensitivity of the CSV method is the catalytic cathodic stripping voltammetry (CCSV), in which catalytic processes were applied to the reduction of accumulated species. This technique was used for the assay of a number of sulphur-containing compounds such as cysteine, glutathione, penicillamine and sulphur-containing amino acids in the presence of nickel ion [24]. Catalytic stripping voltammetry in the presence of nickel involves the deposition of the analyte as a mercury complex that is subsequently reduced during the stripping step. The analyte released catalyses the reduction of nickel. The catalytic reduction occurs at less negative potentials than the diffusion-controlled reduction of hydrated nickel ion. The catalytic reduction of nickel is induced by a large number of compounds with a disadvantage of low selectivity of the analytical methods based on this kind of electrode process. However, CCSV may improve the selectivity because under the conditions of this technique, only compounds that can be accumulated on the electrode surface can be determined. The proper selection of the accumulation potential and the composition of the supporting electrolyte may allow selective determination of related compounds $[25,26]$.

In this work, attempt was made to use the two above mentioned voltammetric techniques, adsorptive stripping voltammetry and catalytic cathodic stripping voltammetry, to develop analytical methods for the determination of timonacic either in pure form or in pharmaceutical preparations.

\section{Experimental \\ Materials and reagents}

Timonacic was obtained from SEDICO (6 October City, Egypt) and was used as such without any purification. Hepaton ${ }^{\circledR}$ tablets SEDICO (6 October City, Egypt) 
and Hepargen ${ }^{\circledR}$ tablets (Abusultan, Ismalia, Egypt) under license from Syntex Pharm. AG (Allscwil, Switzerland), each labeled to contain $100 \mathrm{mg}$ TC, were purchased from the local market. Copper acetate (Fluka, Switzerland) was prepared as $5 \times 10^{-3} \mathrm{M}$ in $2 \% \mathrm{v} / \mathrm{v}$ acetic acid solution. Nickel sulphate (BDH, Poole, UK) was prepared as $6 \times 10^{-2} \mathrm{M}$ in water. Borate buffer was prepared by adjusting the $\mathrm{pH}$ of sodium tetraborate solution with dilute hydrochloric acid or sodium hydroxide solution [27]. Phosphate buffer was prepared by mixing different volumes of $0.067 \mathrm{M}$ solutions of potassium dihydrogen phosphate and disodium phosphate [27].

\section{Apparatus}

Metrohm 693 VA Processor with a model 694 VA Stand assembly containing a multimode electrode in the hanging mercury drop electrode (HMDE) as working electrode, a $\mathrm{Pt}$ rod as auxiliary electrode and a reference $\mathrm{Ag} / \mathrm{AgCl} / 3 \mathrm{M} \mathrm{KCl}$ electrode. Schott-Ceräte pH meter Model CG 710 calibrated with standard buffers was also used.

\section{Standard stock solution}

Timonacic solution was prepared as $0.32 \mathrm{mg} \mathrm{mL}^{-1}$ in hot water. The solution was further diluted to obtain a standard solution of $32 \mu \mathrm{g} \mathrm{mL} \mathrm{m}^{-1}$.

\section{Tablets solution}

Twenty tablets were weighed and an amount of finely powdered tablets equivalent to $32 \mathrm{mg}$ was transferred to a $100 \mathrm{~mL}$ volumetric flask. About $50 \mathrm{~mL}$ hot distilled water were added and the suspension was sonicated for $15 \mathrm{~min}$ and diluted to volume with water. Further dilution was made to obtain a solution of $32 \mu \mathrm{g} \mathrm{mL} \mathrm{m}^{-1}$.

\section{Procedure for construction of calibration curve}

Into the polarographic cell, $10 \mathrm{~mL}$ of buffer solution (borate buffer $\mathrm{pH} 8.5$ and phosphate buffer $\mathrm{pH} 7$ in the case of CSV and CCSV method, respectively) were introduced followed by the appropriate amount of the metal solution. The mixture was deareated by passing nitrogen gas through it for $5 \mathrm{~min}$. A new mercury drop was formed and the accumulation developed in the stirred solution, with the accumulation potential close to $-300 \mathrm{mV}$ and $-100 \mathrm{mV}$ (for the CSV and CCSV method, respectively). The solution was left for $10 \mathrm{sec}$ with no stirring, then differential pulse scan towards more negative potential values was performed. The stripping voltammogram of the blank was recorded and the procedure was repeated after the successive addition of (TC) in the concentration range of $3.2-11.2 \mathrm{ng} \mathrm{mL}^{-1}$ or $16-224.0 \mathrm{ng} \mathrm{mL}^{-1}$ for the CSV and CCSV method, respectively. 


\section{Results and discussion}

\section{The adsorptive stripping voltammetric method}

In Fig. 1, the stripping voltammograms of $16 \mathrm{ng} \mathrm{mL}^{-1}$ (TC) obtained in the absence and presence of copper(II) ions are shown. Accumulation was performed at $-300 \mathrm{mV}$ for $1 \mathrm{~min}$ at $\mathrm{pH} 8.5$ (using borate buffer). In the absence of copper(II) ion, the stripping peak due to the reduction of mercury complex appears at $-610 \mathrm{mV}$. As can be seen in Fig. 1, a new peak negative to the initial one at $-773 \mathrm{mV}$ develops after the addition of copper(II) ions. The height of the peak is dependent on the (TC) and copper concentrations, $\mathrm{pH}$, accumulation potential and accumulation time.

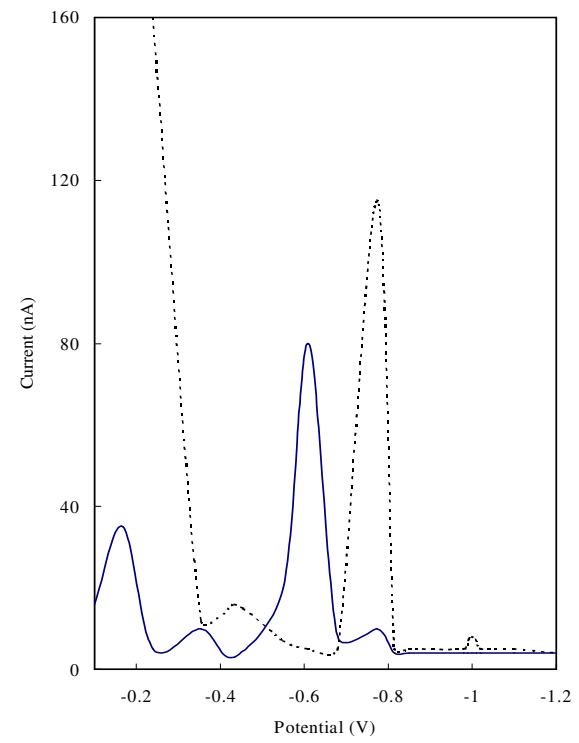

Figure 1. Stripping voltammograms for $16 \mathrm{ng} \mathrm{mL}^{-1}$ (TC) in the absence $(-)$ and presence (-----) of copper(II) $\left(4 \times 10^{-4} \mathrm{M}\right)$ (borate buffer $\left.\mathrm{pH}=8.5\right)$.

Forsman found that current enhancement in the presence of copper is due to the adsorption of copper(I) amino acid complexes [28]. This finding was confirmed by Househam et al. [29], as they suggested that the cathodic peak for cystine or cysteine in the presence of copper be due to the reduction of the adsorbed copper(I) cysteinate complex. In analogy, we can suggest that the electrolysis of (TC) in the presence of copper is due to the generation of copper(I) at the electrode surface, then the formation of copper(I)-(TC) complex that is adsorbed on the (HMDE) during the subsequent negative potential sweep. This copper(I) complex is reduced, allowing the drug to be determined indirectly.

$$
\begin{aligned}
& \mathrm{Cu}^{+2}+\mathrm{TC}+\mathrm{e}^{-} \rightarrow \mathrm{Cu}^{+} \mathrm{TC} \text { (ads) } \\
& \mathrm{Cu}^{+} \mathrm{TC}(\mathrm{ads})+\mathrm{Hg}+\mathrm{e}^{-} \rightarrow \mathrm{Cu} / \mathrm{Hg}+\mathrm{TC}
\end{aligned}
$$

The reaction stoichiometry between copper ions and (TC) has been determined by applying the Asmus method [30]. The formation of 1:1 ratio runs parallel to the previous explanation (Fig. 2). 


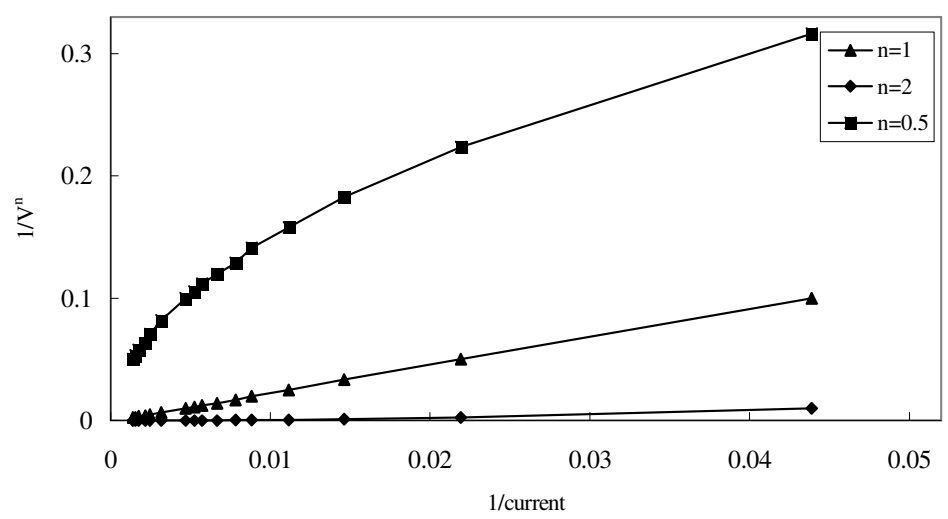

Figure 2. Asmus method for determination of the stoichiometry of (TC)-copper system.

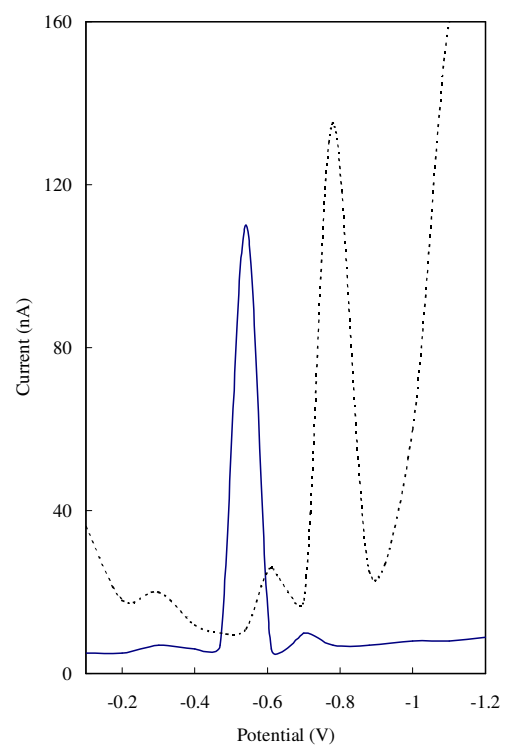

Figure 3. Stripping voltamogram of $128 \mathrm{ng} \mathrm{mL}^{-1}$ (TC) in the absence $(-)$ and presence (-----) of nickel (phosphate buffer $\mathrm{pH} 7$ ).

\section{The catalytic cathodic stripping voltammetric method}

Preliminary studies showed that (TC) accumulates effectively at $-100 \mathrm{mV}$ in phosphate buffer (Fig. 3). However, after the addition of nickel(II), this ion exerts an inhibiting effect on the cathodic stripping peak of mercury thiolate at $-534 \mathrm{mV}$ and forms a second peak, the catalytic peak, at $-782 \mathrm{mV}$. This peak is observed in the presence of a large excess of nickel as compared with (TC).

Bănica studied the effect of the nickel ion on the CSV of some sulphur containing amino acids and peptides [24] and he suggested that the nickel ion suppresses the cathodic stripping of mercury thiolate for ligands, giving very stable nickel chelates. The newly appeared peak was the result of ligand as a nickel complex rather than as a mercury complex.

The proposed mechanism of catalytic reduction is as follows:

1. accumulation of mercury thiolate derivative of (TC) 
$\mathrm{Hg}+2 \mathrm{TC} \rightarrow \mathrm{Hg}(\mathrm{TC})_{2}+2 \mathrm{H}^{+}+2 \mathrm{e}^{-}$

2. reduction of mercury thiolate during the cathodic potential sweep

$\mathrm{Hg}(\mathrm{TC})_{2}+2 \mathrm{H}^{+}+2 \mathrm{e}^{-} \rightarrow \mathrm{Hg}+2 \mathrm{TC}$

3 . formation of the nickel-thiol complex by the previously released thiol

$\mathrm{Ni}^{+2}+2 \mathrm{TC} \rightarrow \mathrm{Ni}(\mathrm{TC})_{2}+2 \mathrm{H}^{+}$

4. the catalytic reduction of nickel in this complex

$\mathrm{Ni}(\mathrm{TC})_{2}+2 \mathrm{H}^{+}+2 \mathrm{e}^{-} \rightarrow \mathrm{Ni}^{\circ}+2(\mathrm{TC})$

The reaction stoichiometry was determined by applying Asmus method. It was found that the ratio of (TC) : nickel is $2: 1$ (Fig. 4).

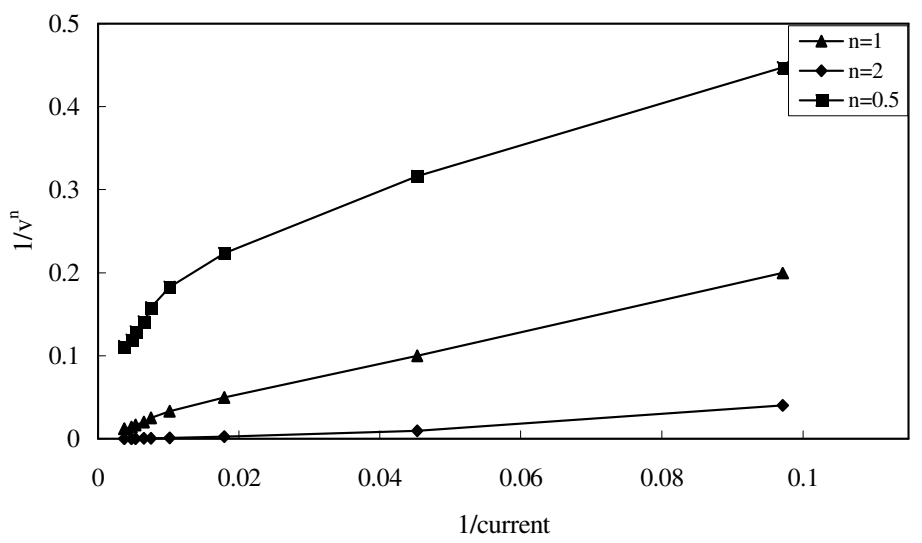

Figure 4. Asmus method for determination of the stoichiometry of (TC)-nickel system.

\section{Optimum conditions}

Effect of metal ion concentration

The metal concentration varied from $5 \times 10^{-7}$ to $1 \times 10^{-5} \mathrm{M}$ and $6 \times 10^{-5}$ to $6 \times 10^{-4} \mathrm{M}$ in the case of copper and nickel, respectively (Fig. 5).

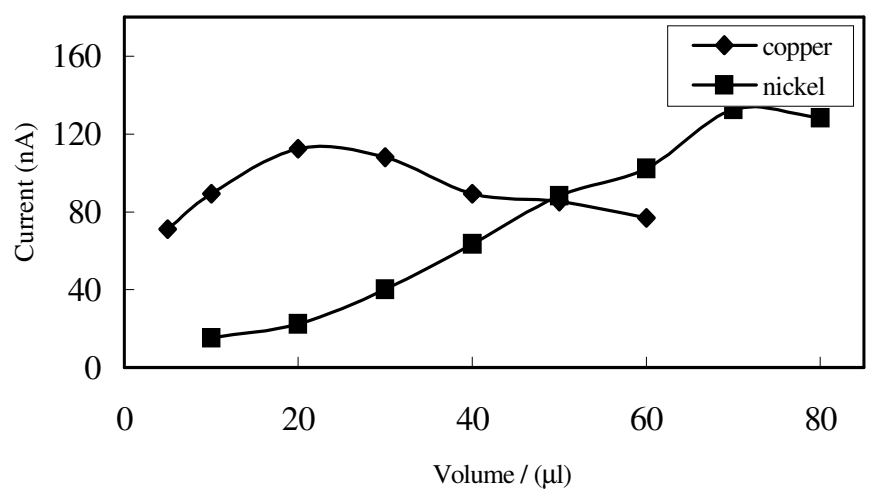

Figure 5. Effect of metal volume on the cathodic stripping peak of (TC), [(TC) $=16 \mathrm{ng}$ $\mathrm{mL}^{-1}$ or $128 \mathrm{ng} \mathrm{mL}^{-1}$ in the presence of copper or nickel, respectively].

The reduction peak of copper(I)-(TC) complex increased with increasing copper concentration up to about $5 \times 10^{-6} \mathrm{M}$, above which the peak height decreased. This may be due to the competition between the two reactions ( $\mathrm{Cu} \mathrm{Hg}$ and $\mathrm{Cu} \mathrm{TC}$ ) for the electrode surface. 
In the case of nickel, the optimum nickel concentration was $4.2 \times 10^{-4} \mathrm{M}$ as with higher nickel concentrations, the main nickel peak tends to overlap the catalytic peak, especially at very low concentrations of (TC) (Fig. 5).

\section{Effect of $p H$}

The effect of $\mathrm{pH}$ on the peak height and peak potential was studied using borate and phosphate buffers. The maximum height was observed for [copper(I)-(TC)] complex at $\mathrm{pH}=8.5$ using borate buffer (Fig. 6). The peak potential of complex became more negative as the $\mathrm{pH}$ increased. For catalytic peak, the optimum $\mathrm{pH}$ was found to be 7 using phosphate buffer (Fig. 6). Higher $\mathrm{pH}$ values were avoided to prevent the hydrolysis of nickel(II).

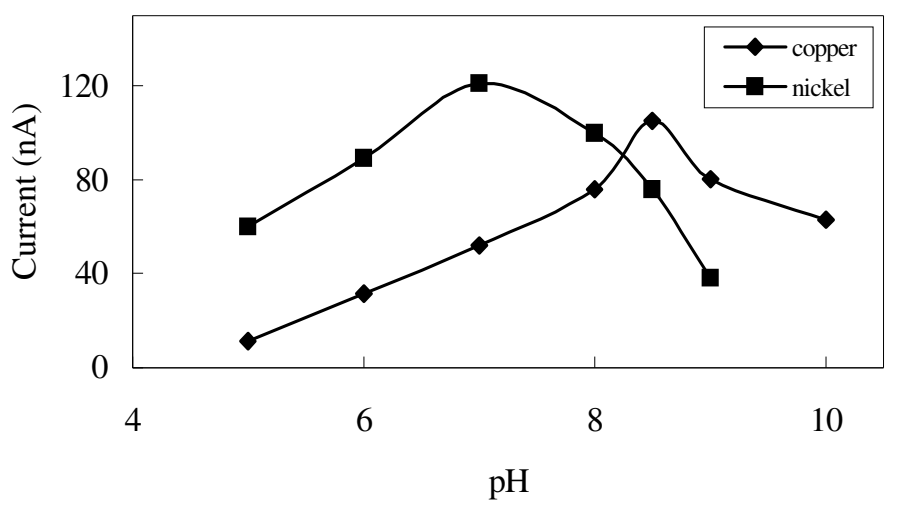

Figure 6. Effect of $\mathrm{pH}$ on the cathodic stripping peak current of (TC), [(TC) $=16 \mathrm{ng}$ $\mathrm{mL}^{-1}$ or $128 \mathrm{ng} \mathrm{mL}^{-1}$ in the presence of copper or nickel, respectively].

\section{Effect of accumulation potential}

The influence of different accumulation potentials on the height of the two peaks was studied between 0.0 and $-400.0 \mathrm{mV}$. Maximum responses were obtained at accumulation potentials of $-300 \mathrm{mV}$ or $-100 \mathrm{mV}$ in the presence of copper or nickel ions, respectively (Fig 7).

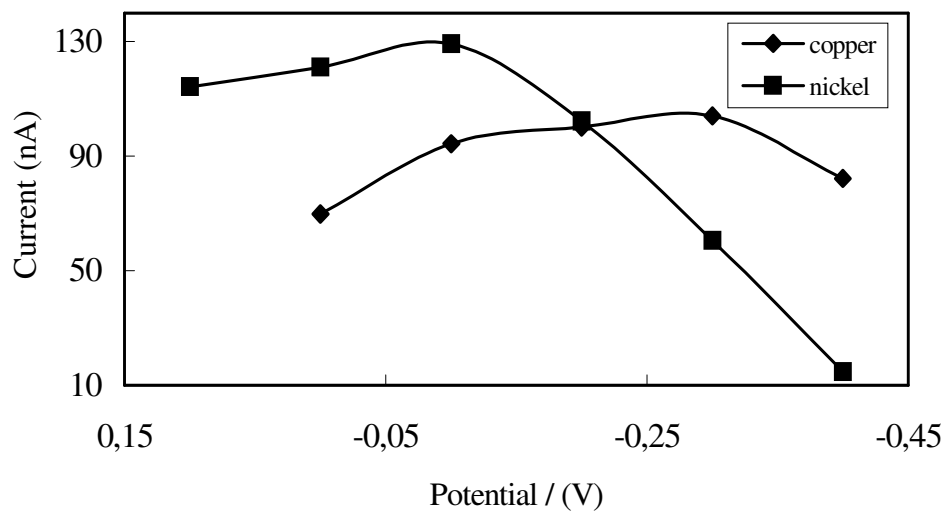

Figure 7. Effect of the accumulation potential on the peak current of (TC)-metal, [(TC) $=16 \mathrm{ng} \mathrm{mL}^{-1}$ or $128 \mathrm{ng} \mathrm{mL}^{-1}$ in the case of copper or nickel, respectively].

With accumulation potentials more negative than the reduction potentials of the cathodic stripping peak or the catalytic stripping peak, the peaks were no longer 
observed. More positive potentials were avoided in the case of copper as the free copper peak increased with a consequent increase in the base line of the complex peak.

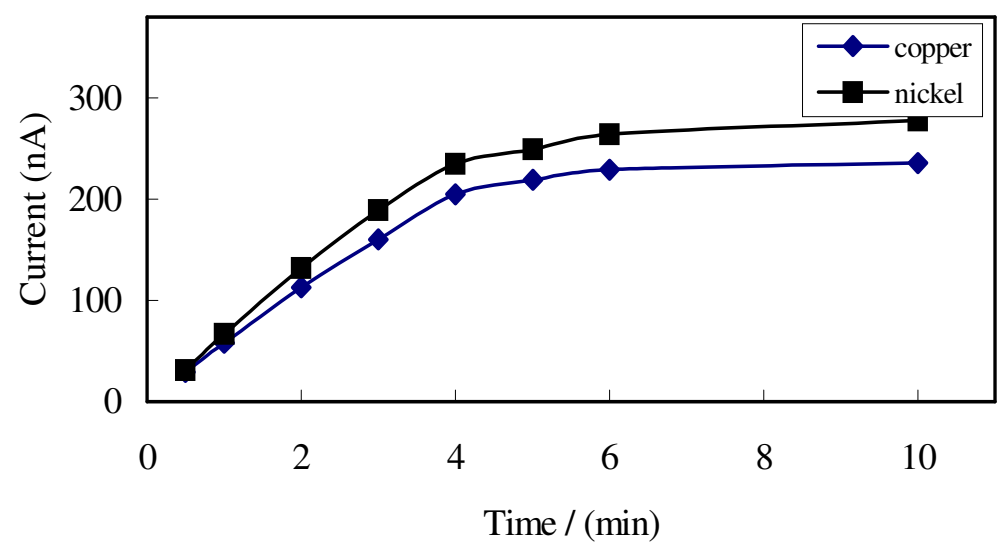

Figure 8. Effect of the accumulation time on the peak current of (TC)-metal, [(TC) $=16$ $\mathrm{ng} \mathrm{mL} \mathrm{L}^{-1}$ or $128 \mathrm{ng} \mathrm{mL}^{-1}$ in the case of copper or nickel, respectively].

\section{Effect of accumulation time}

The effect of accumulation time is shown in Fig. 8. The peak height is increased rectilinearly with accumulation time up to $4 \mathrm{~min}$ (critical time). At longer accumulation time rectilinearity was lost.

\section{Validation of the proposed methods}

\section{Linearity}

Under the optimum experimental conditions, the peak height in the presence of either copper or nickel is directly proportional to (TC) concentration over a wide range (Table 1). Linearity plots were constructed to determine the linear working range of the calibration curves (Fig. $9 \mathrm{a}$ and b). The two curves show two parallel dotted control lines representing the acceptable upper and lower error limits for the analysis. They were placed on the plot to determine the acceptable working range.

\section{Accuracy}

The accuracy of the proposed methods was evident from the values of the recoveries of (TC) spiked with commonly used tablet excipients (Table 1).

\section{Precision}

The repeatability of the proposed methods was evaluated by calculating the relative standard deviation of the assay results of three different concentrations, each in three replicates. The results are presented in Table 1. 
Table 1. Statistical data of the regression equations for timonacic chelates.

\begin{tabular}{|l|c|c|}
\hline \multicolumn{1}{|c|}{ Item } & AdSV & CCSV \\
\hline Linearity range $\left(\mathrm{ng} \mathrm{mL}^{-1}\right)$ & $3.2-112.0$ & $16.0-224.0$ \\
Regression equation & & \\
Intercept (a) (nA) $\mathrm{a} \pm \mathrm{tS}_{\mathrm{a}}$ & $19.86 \pm 8.491$ & $-2.398 \pm 8.594$ \\
Slope (b) (mV) $\mathrm{b} \pm \mathrm{tS}_{\mathrm{b}}$ & $5.737 \pm 32.65$ & $0.962 \pm 7.53$ \\
Correlation coefficient (r) & 0.9983 & 0.9980 \\
& & \\
Accuracy (mean $\pm \mathrm{S} . \mathrm{D})$. & $99.52 \pm 0.94$ & $100.48 \pm 0.78$ \\
Precision (RSD\%) & 0.53 & 0.82 \\
Limit of detection (LOD) & 1.5 & 13.6 \\
Limit of quantitation (LOQ) & 4.9 & 43.5 \\
\hline
\end{tabular}
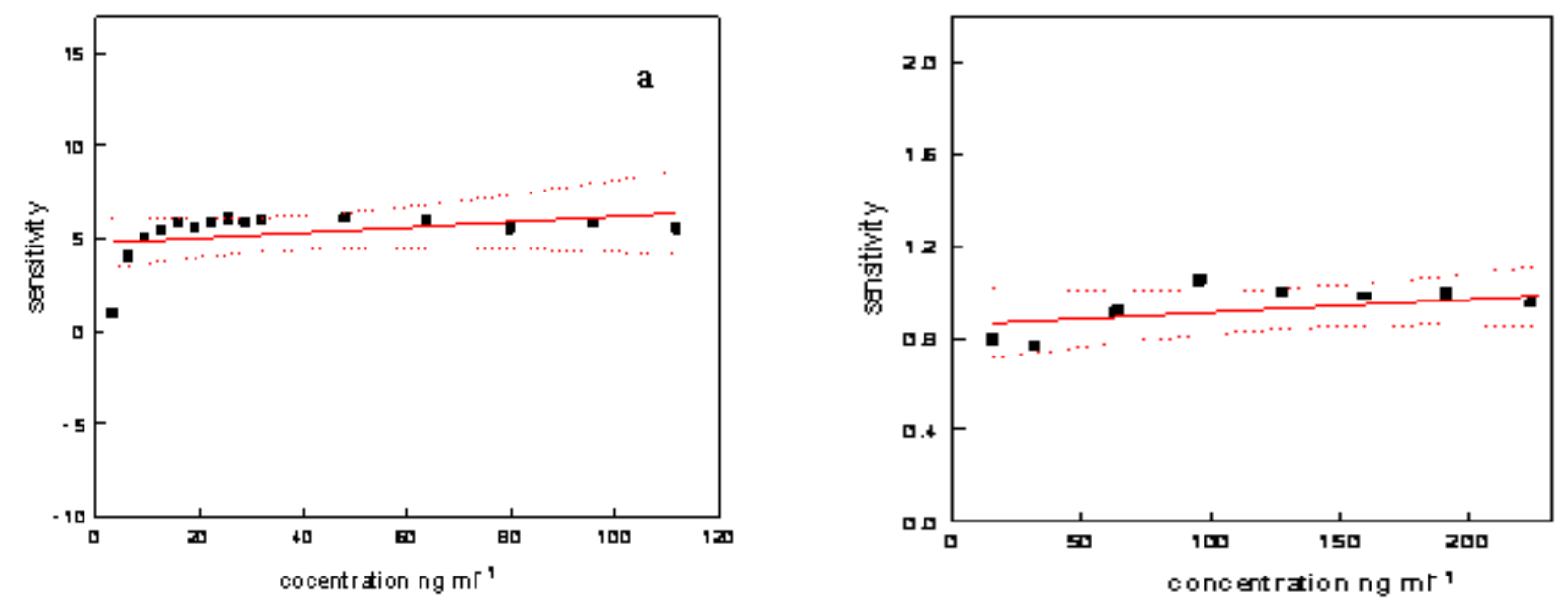

Figure 9. Linearity plots for the determination of (TC) using AdSV (a) and CCSV (b).

\section{Limit of detection and limit of quantitation}

The LOD ( $3 \sigma$; where $\sigma$ is the standard deviation of blank) and the LOQ (at a $\mathrm{RSD}=2 \%$ ) are presented in Table 1 .

\section{Analytical application}

The proposed methods have been applied for the analysis of (TC) in its commercial tablets. Statistical analysis of the results obtained by the proposed methods and those obtained with the reported colorimetric method [9] was performed using student's t-test and the variance ratio F-test (Table 2). The calculated values did not exceed the theoretical ones, indicating no significant difference between the compared methods. 
Table 2. Application of the proposed voltammetric methods to the assay of pharmaceutical dosage forms.

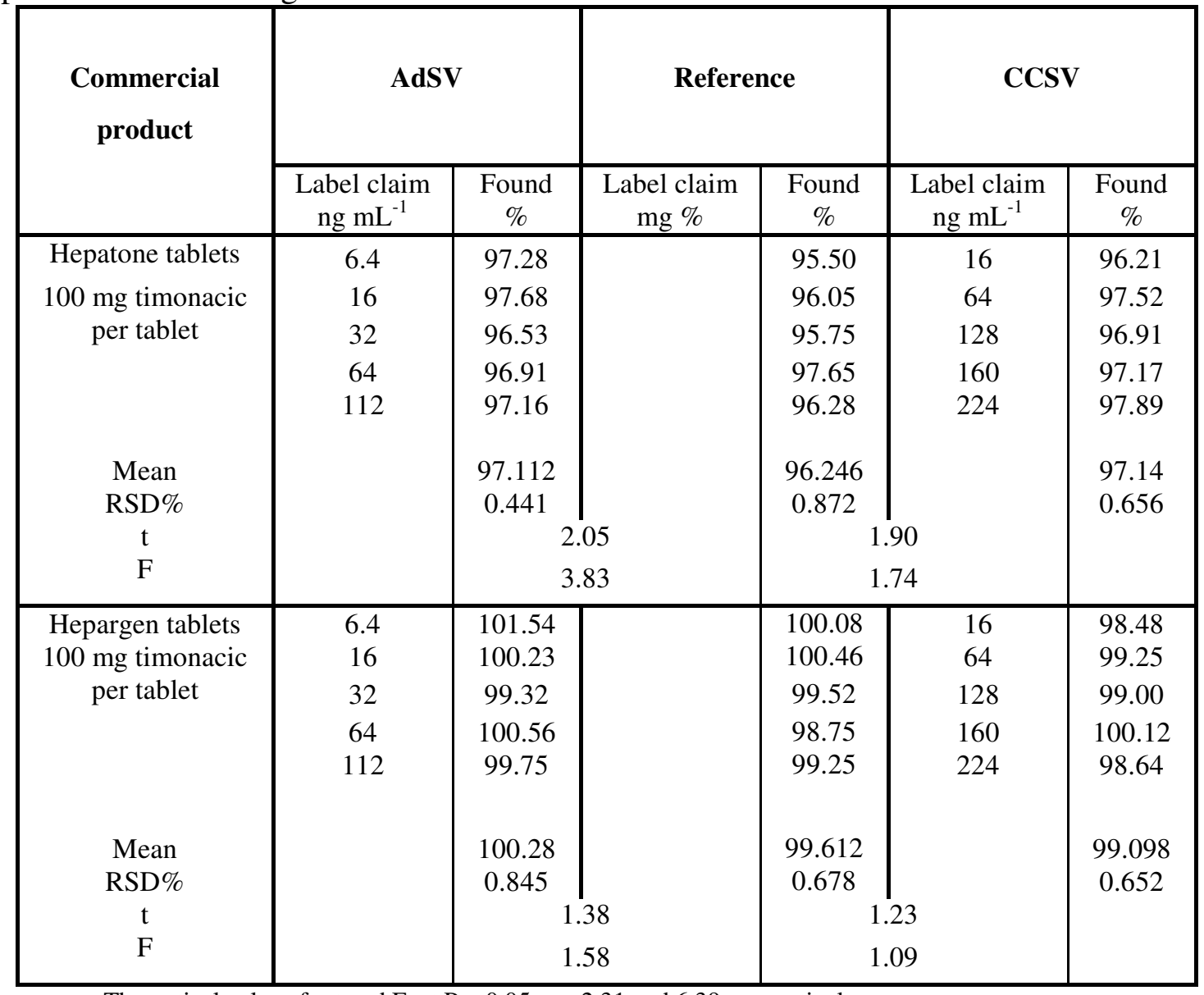

Theoretical values for $\mathrm{t}$ and $\mathrm{F}$, at $\mathrm{P}=0.05$, are 2.31 and 6.39 , respectively.

\section{Conclusion}

The proposed methods are simple, practical and accurate. The AdSV method is more sensitive than the CCSV one and is of comparable sensitivity with the published GC-MS method [15]. The CCSV and the AdSV are of better selectivity compared with the conventional CSV, as these methods are connected with the ability of the ligand to form a complex with either copper or nickel ions.

\section{References}

1. H.T. Clarke, J.R. Johnson, and R. Robinson, "The Chemistry of Penicillin”, Princeton University Press, Princeton, NJ, 1949.

2. M.L. Zwiesler, J. Med. Chem. 16 (1973) 319-322. 10.1021/jm00262a003

3. J.E.F. Reynolds, (Editor), "Martindale-The Extra Pharmacopoeia", $31^{\text {st }}$ Edition, The Pharmaceutical Press, London, 1996.

4. A. Bruguerlas, P. Alberti, Proc. Am. Assoc. Cancer Res. 21 (1980) 621627.

5. A.C. Garcia, P.T. Blanco, J. Electroanal. Chem. Interfacial Electrochem. 245 (1988) 157-166. 10.1016/0022-0728(88)80067-6 
6. Z.J. Karpinski, J. Radomski, Anal. Lett. 22 (1989) 2291-2306. 10.1080/00032718908051256

7. J. Zhang, H. Pang, Z. Cui, Yaowu Fenxi Zazhi 10 (1990) 298-299.

8. R.S. Bakry, O. Abdel Razak, A.M. El Walily, S.F. Belal, Acta Pharm. Pol. 52 (1995) 265-269.

9. R.S. Bakry, O.A. Razak, A.M. El Walily, S.F. Belal, STP Pharma. Sci. 5 (1995) 397-402.

10. A.F.M. El Walily, O.A. Razak, S.F. Belal, R.S. Bakry, Quimica Analitica 19 (2000) 43-47.

11. R.S. Bakry, O. Abdel Razak, A.M. El Walily, S.F. Belal, J. Pharm. Biomed. Analysis 17 (1998) 95-101. 10.1016/S0731-7085(97)00172-6

12. Y.H. Ha, J.S. Jin, Y.J. Song, J. Jia, Yaowu Fenxi Zazhi 14 (1994) 52-53.

13. J. Lankelma, P.G.M. Penders, A. Leyva, H.M. Pinedo, Cancer Lett. 12 (1981) 131-137. 10.1016/0304-3835(81)90048-3

14. L. Terzuoli, R. Pagani, R. Leoncini, D. Vannoni, E. Marinello, J. Chromatography A 514 (1990) 80-85. 10.1016/S0021-9673(01)89379-1

15. S. Ho-Sang, A. Hye-Sil, L. Byung-Hoon, J. Mass Spectrom. 42 (2007) 1225-32. 10.1002/jms.1255

16. K. Hiroyuki, M. Sayuri, M. Masami, J. Pharm. Biomed. Analysis 15 (1997) 1271-1279. 10.1016/S0731-7085(96)02002-X

17. T.M. Florence, J. Electroanal. Chem. Interfac. 97(2) (1979) 237-25. 10.1016/S0022-0728(79)80065-0

18. J. Incezdy, Analytical application of complex equilibria, Ellis Horwood Ltd., England, p. 137, 1976.

19. R. Von Wandruszka, X. Yuan, M.J. Morra, Talanta 40 (1993) 37-42. 10.1016/0039-9140(93)80140-M

20. C.M.G. Van Den Berg, B.C. Housham, J.P. Riley, J. Electroanal. Chem. Interfac. 239(1-2) (1988) 137-148. 10.1016/0022-0728(88)80275-4

21. U. Forsman, J. Electroanal. Chem. Interfac. 111(2-3) (1980) 325-334. 10.1016/S0022-0728(80)80053-2

22. A.C. Le Gall, C.M.G. Van Den Berg, Analyst 118 (1993) 1411-1415. 10.1039/AN9931801411

23. J.C. Moreira, A.G. Fogg, Analyst 115 (1990) 41-43. 10.1039/AN9901500041

24. F. G. Bănica, A.G. Fogg, J.C. Moreira, Anal. Lett. 29 (1996) 1415-1429. 10.1080/00032719608001491

25. J.C. Bănica, J.C. Moreira, A.G. Fogg, Analyst 119 (1994) 309-318. 10.1039/AN9941900309

26. F.G. Bănica, A.G. Fogg, J.C. Moreira, Analyst 119 (1994) 2343-2349. 10.1039/AN9941902343

27. K. Deim, C. Lentner, Editors, Scientific Tables Documenta Geigy, $7^{\text {th }}$ edition, J. R. Geigy, S.A., Basle, Switzerland, 1970 pp. 280-283.

28. U. Forsman, J. Electroanal. Chem. 111 (1980) 325-335.

29. B.C. Househam, C.M.G. Vandenberg, J.P. Riley, Anal. Chim. Acta 200 (1987) 291-299. 10.1016/S0003-2670(00)83777-0

30. E. Asmus, Fresenius J. Anal. Chem. 178 (1960) 104-116. 10.1007/BF00467200 